\title{
An in vitro method for studying digestion in the pig
}

\section{Simulating digestion in the different compartments of the intestine}

\author{
BY W. LÖWGREN, H. GRAHAM*AND P. AMAN \\ Department of Animal Nutrition and Management, Swedish University of Agricultural \\ Sciences, Box 7024, S-750 07 Uppsala, Sweden
}

(Received 3 February 1988 - Accepted 9 November 1988)

\begin{abstract}
1. An in vitro method, using duodenal and ileal digesta and faeces from pigs as inocula for the preparation of three incubation media for simulating the digestive processes in the pig, was proposed. The kinetics of degradation in these three media of three feed samples (pig-grower diet, sugar-beet pulp and wheat bran) with crude protein (nitrogen $\times 6.25$ ) contents varying from 111 to $196 \mathrm{~g} / \mathrm{kg}$, starch contents from 10 to $446 \mathrm{~g} / \mathrm{kg}$ and dietary fibre contents from 168 to $686 \mathrm{~g} / \mathrm{kg}$, were studied.

2. The method was investigated by incubating the feeds in the three media for up to $96 \mathrm{~h}$, and determining the rate and extent of disappearance of feed components.

3. For each feed the $96 \mathrm{~h}$ dry matter disappearance was almost equal for all media, although the rate of disappearance varied considerably, with ileal digesta the most potent, particularly for the high-fibre feeds, and duodenal digesta the least. The patterns of disappearance of individual components were similar in all media, with the exception of crude protein which was apparently less degraded in ileal and especially faecal media.

4. Results suggest that a combination of a short $(6-12 \mathrm{~h})$ and a long (48-72 h) in vitro incubation could be employed to simulate digestion in the small and large intestine respectively of the pig
\end{abstract}

Traditionally feed evaluation is performed in time-consuming and costly experiments, requiring animals and facilities in proportion to the accuracy wanted. In vitro techniques with rumen fluid or substitutes have been routinely and extensively used for the evaluation of ruminant feed. In recent years, in vitro methods for the evaluation of feeds for simplestomached animals have been developed using either contents of the pig stomach and different parts of the small and large intestine (Vervaeke et al. 1979; Holzgraefe et al. 1985) or blends of pepsin and hydrochloric acid in combination with pig intestinal fluid (Furuya et al. 1979; Clunies \& Leeson, 1984) as inocula for incubations. These methods have been shown to be well correlated with in vivo apparent faecal digestibilities for dry matter and energy, but no attempts have yet been made to elucidate the patterns of degradation. Since the site of absorption is of major importance for the energetic value of the feed (Just et al. 1983; Mason, 1983), it would be of considerable interest to determine those feed components that are readily digestible in the small intestine and those that are degraded in the hind-gut. Thus, a method is proposed where the former components are determined by incubation for a short period of time, and the latter by incubation for a longer period. However, an understanding of the processes of digestion in vitro is necessary before this or similar methods can be widely used. Thus, the objectives of the present investigation were to provide information on the rate and pattern of disappearance in vitro of different feeds, including a digestible cereal-based pig feed, a degradable fibre (sugar-beet pulp) and a relatively resistant fibre source (wheat bran).

\section{METHODS}

Animals and diets. Two mature female crossbred pigs (Swedish Landrace $\times$ Large White) fitted with steel, replaceable ' $T$ '-shaped intestinal cannulas, just distal to the pancreatic and

$$
\text { * For reprints. }
$$


bile ducts (duodenal) and about $150 \mathrm{~mm}$ before the ileo-caecal junction, were used as donors of digesta and faeces. The pigs were fed at 08.00 and 16.00 hours with $1 \mathrm{~kg}$ daily of a commercially available pelleted pig feed containing $(\mathrm{g} / \mathrm{kg}$ fresh weight): 266 each of barley, wheat and oats, 60 each of peas (Pisum sativum L.) and soya-bean meal, 50 fishmeal and 32 vitamin and mineral supplement (for further details, see Graham et al. 1986a). In the in vitro experiments three feeds were examined: the previously mentioned pig feed (SLU Foderfabrik, Uppsala), sugar-beet pulp (Fibrex; Sockerbolaget, Arlöv) and wheat bran (Kungsörnen AB, Uppsala). The experimental feeds were milled in a Brabender mill with a $1.0 \mathrm{~mm}$ screen before the in vitro experiments.

In vitro method. The in vitro method employed was based on that developed by Lindgren (1979) for ruminant studies, using the same buffer and apparatus. The basic method is described immediately below, and alternatives investigated are described under Expts 1, 2 and 3.

Inocula sampling. Digesta were collected by placing a rubber balloon on the respective cannula. The duodenal digesta were collected between 09.00 and 10.00 hours, and a sufficient sample was generally obtained in less than $10 \mathrm{~min}$. The ileal digesta were collected between 12.00 and 13.00 hours, and sampling usually took about $30 \mathrm{~min}$. Defaecation usually occurred as a result of increased activity between the digesta sampling periods, and faeces were collected in as fresh a state as possible immediately after defaecation. Inocula from the two pigs were pooled for the respective incubation medium.

Preparation of incubation media. Duodenal digesta were weighed, filtered through two layers of cheesecloth and diluted in 4 parts $(\mathrm{w} / \mathrm{w})$ of a buffer solution $\left(\mathrm{mmol} / 1 ; \mathrm{NaHCO}_{3}\right.$ $101 \cdot 2, \mathrm{~K}_{2} \mathrm{HPO}_{4} 33 \cdot 3,\left(\mathrm{NH}_{4}\right)_{2} \mathrm{HPO}_{4} 3 \cdot 8, \mathrm{NaCl} 17 \cdot 1, \mathrm{MgSO}_{4} \cdot 7 \mathrm{H}_{2} \mathrm{O} 2 \cdot 0$ (Lindgren, 1979)). Ileal digesta and faeces were weighed and suspended in sufficient buffer to enable filtration, after which the filtrates were centrifuged at $90 \mathrm{~g}$ for $5 \mathrm{~min}$, the supernatant fractions decanted and added to buffer corresponding to 4 parts (by wt) of the initial digesta-faeces weight. The buffer solution was freshly prepared, maintained at $38^{\circ}$ and flushed with carbon dioxide for at least $2 \mathrm{~h}$ before incubation. The $\mathrm{pH}$ was adjusted to 6.9 .

Incubation procedure. Incubation medium $(50 \mathrm{ml})$ was poured into the preweighed digestion tube containing $0.5 \mathrm{~g}$ of the experimental feed. The digestion tube was fitted with a grade no. 2 glass filter and enclosed by a rubber stopper at each end, the upper stopper fitted with a one-way valve to release excess gas (Lindgren, 1979). The digestion tube was placed in a water-bath at $38^{\circ}$, and gently agitated occasionally in order to keep the feed suspended in the medium. The incubation was terminated by filtering the liquid through the glass filter and washing the residue three times with $50 \mathrm{ml}$ cold distilled water. In Expt 2 the residue was additionally washed twice with $15 \mathrm{ml}$ acetone.

The dry residues and a simultaneously incubated blank residue were determined gravimetrically in the digestion tube after subtracting the weight of the tube. Blank residue was the increase in weight for a digestion tube after incubation with the respective inocula for 24 (duodenal) and $48 \mathrm{~h}$ (ileal and faecal). By subtracting the blank from the feed residue the dry matter disappearance (DMD) was calculated.

\section{Expt 1}

The effect of centrifuging ileal inocula at $0,60,90$ and $365 g$ for $5 \mathrm{~min}$ on in vitro DMD $(n \geqslant 4)$ from the pig feed after $20 \mathrm{~h}$ incubation was investigated.

The effect of grinding with different screen sizes on in vitro DMD was evaluated using barley grain milled to pass 5.0, 2.0, 1.0 and $0.5 \mathrm{~mm}$ screens. Samples $(n 3)$ were incubated with duodenal, ileal and faecal inocula for five periods of time from 1 to $72 \mathrm{~h}$. Additionally the barley was washed with buffer solution ( $n$ 6).

The effect on in vitro DMD of lowering the initial $\mathrm{pH}$ of buffer from the original 6.9 to $5 \cdot 9$, by adding $0 \cdot 1$ M-hydrochloric acid, $(n \geqslant 5)$ was investigated. 
The solubility of the three feeds after 24 and $48 \mathrm{~h}$ of incubation ( $n$ 3) in buffer solution was also investigated.

\section{Expt 2}

The feeds were incubated with the three different inocula for periods of time up to $96 \mathrm{~h}$. After incubation the $\mathrm{pH}$ of the buffer was determined, and the undegraded residue was recovered, dried and weighed to determine DMD. The incubations were performed three times in duplicate $(n 6)$.

\section{Expt 3}

The disappearance of chemical components and the production of metabolites during the degradation were investigated. Four incubation times were chosen, from the previous experiment, to divide the range of DMD into four approximately equal parts. Each feed and inoculum were run independently in as many replicates $(n-14)$ as were needed to provide about $2 \mathrm{~g}$ residues at each incubation time. A zero-time sample was obtained by washing with water and acetone as described previously (p. 674). At the onset and termination of the incubation, a portion of the medium was taken, chilled, centrifuged $(17300 \mathrm{~g}$ for $15 \mathrm{~min})$, frozen and later analysed for organic acids and ethanol. The production of organic acids during the incubation was calculated by subtracting the content present in the inoculum before incubation. Following incubation, residues were washed with cold water and acetone as described previously, air-dried, weighed and pooled by incubation time, feed and inoculum before analysis.

\section{Chemical analysis}

Before analyses, residues were ground in a Tecator cyclone sample mill to pass a $0.5 \mathrm{~mm}$ screen. Dry matter was determined by oven-drying at $105^{\circ}$ for $16 \mathrm{~h}$, and all analyses are reported on a dry matter basis. Crude protein (Kjeldahl- $\mathrm{N} \times 6.25)$ and ash in the feeds were determined according to standard methods (Association of Official Analytical Chemists, 1975). Crude fat was extracted with diethyl ether after acid hydrolysis (Anon., 1971) and gross energy was determined using an adiabatic bomb calorimeter (Gallenkamp, England).

Soluble sugars, including glucose, fructose, sucrose and fructans, were extracted with acetate buffer $(0.05 \mathrm{M} ; \mathrm{pH} 5)$ and determined enzymatically (Larsson \& Bengtsson, 1983). Starch in $80 \%$ ethanol-extracted samples was degraded with a thermostable $\alpha$-amylase (EC 3.2.1.1; Termamyl; Novo A/S, Denmark) and an amyloglucosidase (EC 3.2.1.3; Boehringer Mannheim, West Germany), and the released glucose determined by the glucose oxidase (EC 1.1.3.4) method (Åman \& Hesselman, 1984). Following starch hydrolysis, soluble polymers were precipitated in cold $80 \%$ ethanol and the total dietary fibre content was determined by the method of Theander \& Aman (1979), as modified by Theander \& Westerlund (1986), in which the neutral non-starch polysaccharide (NSP) residues are quantified as alditol acetates by gas-liquid chromatography and Klason lignin gravimetrically. Uronic acid residues were estimated by decarboxylation of the unhydrolyzed samples (Theander \& Åman, 1979). Organic acids and ethanol in the incubation media were quantified by high-performance liquid chromatographic analysis. A filtrate $(20 \mu 1)$ of the incubation medium was injected onto a Biorad Amnex HPX-87H column at $45^{\circ}$, with a flow rate of $0.4 \mathrm{ml}$ eluent $(0.005 \mathrm{M}$-sulphuric acid)/min, and the refractive index was measured using a Tecator RI 5902 refractometer (K. Larsson and B. Andersson, personal communication).

\section{Statistical analysis}

The statistical methods used in Expt 1 were according to Dunn \& Clark (1974). The means were compared pairwise by a $t$ test using the pooled estimates of variances, while an $F$ test 
Table 1. Chemical composition ( $\mathrm{g} / \mathrm{kg} d r \mathrm{y}$ weight) of the experimental feeds investigated

\begin{tabular}{lrrr}
\hline & $\begin{array}{c}\text { Pig } \\
\text { feed }\end{array}$ & $\begin{array}{c}\text { Sugar-beet } \\
\text { pulp }\end{array}$ & $\begin{array}{c}\text { Wheat } \\
\text { bran }\end{array}$ \\
\hline Crude protein (nitrogen $\times 6.25)$ & 196 & 111 & 150 \\
Ash & 58 & 34 & 55 \\
Fat & 36 & 20 & 56 \\
Starch & 446 & 10 & 180 \\
Soluble sugars* & 35 & 50 & 58 \\
Klason lignin & 19 & 27 & 95 \\
NSP residues & & & \\
$\quad$ Rhamnose & 19 & 19 & $\operatorname{tr}$ \\
Arabinose & 19 & 181 & 82 \\
$\quad$ Xylose & 29 & 14 & 121 \\
Mannose & 6 & 13 & 9 \\
$\quad$ Galactose & 11 & 52 & 11 \\
$\quad$ Glucose & 71 & 193 & 120 \\
$\quad$ Uronic acids & 11 & 185 & 18 \\
Dietary fibre $\dagger$ & 168 & 686 & 458 \\
\hline
\end{tabular}

NSP, non-starch polysaccharide; tr, less than $5 \mathrm{~g} / \mathrm{kg}$ present.

* Fructose, glucose, sucrose plus fructans.

† Sum of NSP and Klason lignin.

was used to test the equality of the variances. In Expts 2 and 3 the procedure 'means' of the Statistical Analysis System (SAS Institute Inc., 1982) was used.

\section{RESULTS}

The pigs were healthy and ate well during the experiments.

Starch $(446 \mathrm{~g} / \mathrm{kg})$ was the main component of the pig feed employed, with protein $(196 \mathrm{~g} / \mathrm{kg})$ and dietary fibre $(168 \mathrm{~g} / \mathrm{kg})$ the other major constituents (Table 1). Glucose, from cellulose and mixed-linked $\beta$-glucans, and xylose, from arabinoxylans, were the main NSP residues. The sugar-beet pulp was composed predominantly of dietary fibre $(686 \mathrm{~g} / \mathrm{kg})$, with glucose, mainly from cellulose, and uronic acid and arabinose, mainly from pectic substances, as the major NSP residues. Dietary fibre was also the main component in the wheat bran $(458 \mathrm{~g} / \mathrm{kg})$, with substantial quantities of starch $(180 \mathrm{~g} / \mathrm{kg})$ and crude protein $(150 \mathrm{~g} / \mathrm{kg})$ also present. As in the pig feed, glucose residues from cellulose and xylose residues from arabinoxylans were predominant, with a considerable contribution from Klason lignin $(95 \mathrm{~g} / \mathrm{kg})$.

\section{Expt 1}

Centrifugation of ileal inoculum before incubation gave a higher in vitro DMD $(P<0.05)$ than uncentrifuged inoculum $(0.797 v .0 .753 ;$ SE 0.012$)$, but no difference was found between inocula centrifuged between 60 and $325 \mathrm{~g}$. However, the variability of the DMD was reduced $(P<0.05)$ by centrifugation at $90 \mathrm{~g}$ or higher.

There were large differences in buffer solubility, including particle loss, of barley grain ground to pass 5, 2, 1 and $0.5 \mathrm{~mm}$ screens, i.e. 0.08 (SE 0.007), 0.23 (SE 0.005), 0.44 (SE 0.006) and 0.54 (SE 0.013) respectively. For all three incubation media the effect of screen size on DMD was not significant when the incubations lasted longer than $45 \mathrm{~h}$, or longer than $20 \mathrm{~h}$ except for the material ground to pass the $5 \mathrm{~mm}$ screen (Fig. 1). Standard errors of the means did not exceed 0.020 , and on average were $0 \cdot 011$. 


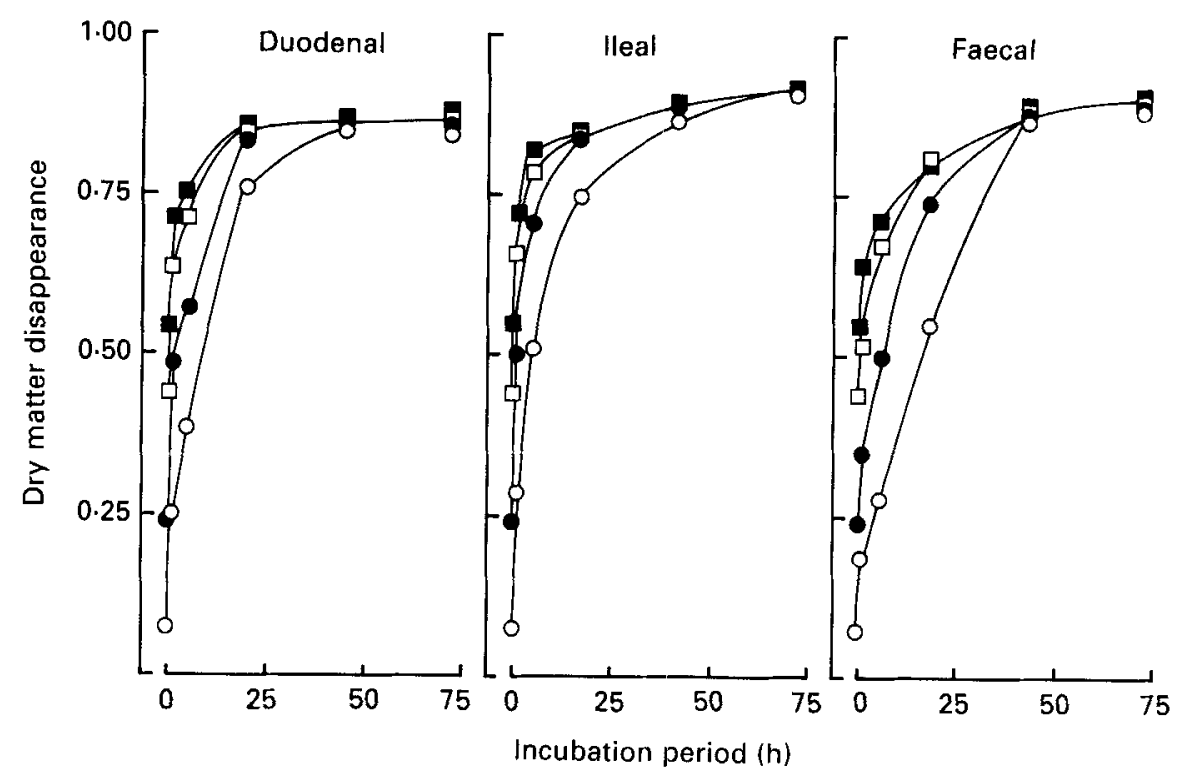

Fig. 1. Expt 1. In vitro dry matter disappearance of barley grain, milled to pass $5(\bigcirc), 2(\bigcirc), 1(\square)$ and 0.5 ( $\mathrm{mm}$ screens, incubated with duodenal, ileal and faecal inocula. For details of procedures, see p. 674 .

Table 2. Expt 1. The effect of initial buffer pH (6.9 or 5.9) on in vitro dry matter disappearance of the pig feed $\dagger$

(Mean values with their standard errors)

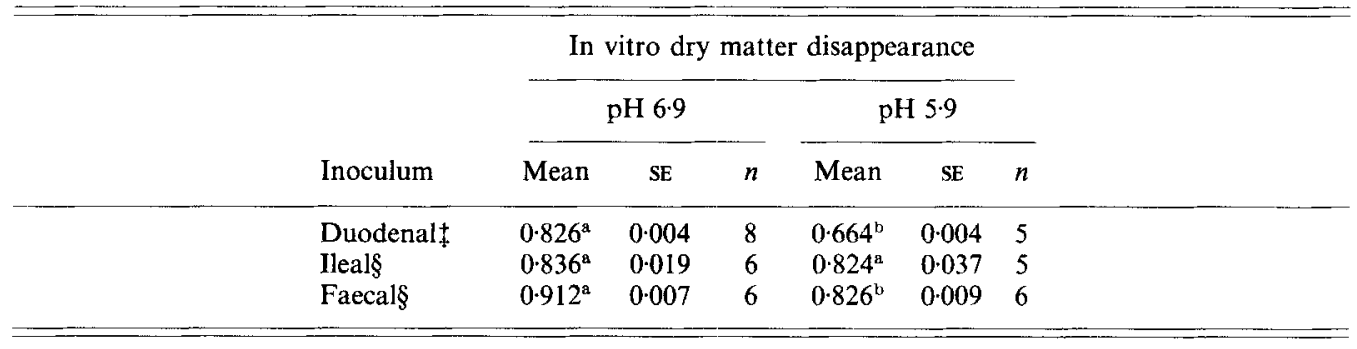

a. b Means within the same row with different superscript letters were significantly different: $P<0.05$.

$\dagger$ For details of procedures, see p. 674.

$\ddagger$ Incubated for $24 \mathrm{~h}$.

$\S$ Incubated for $48 \mathrm{~h}$.

Lowering the initial $\mathrm{pH}$ of the buffer solution had no positive effect on DMD in any of the incubation media, as shown in Table 2 . The DMD was significantly higher $(P<0.05)$ with duodenal and faecal media prepared with the original buffer solution ( $\mathrm{pH} \mathrm{6.9)}$ than with the modified buffer ( $\mathrm{pH} 5 \cdot 9$ ).

Incubation for $24 \mathrm{~h}$ with buffer without added inoculum resulted in a DMD of 0.55 (SE 0.020), 0.10 (SE 0.001) and 0.40 (SE 0.004) for the pig feed, sugar-beet pulp and wheat bran respectively, i.e. slightly higher than the water solubilities, which were $0.42,0.08$ and 0.26 respectively. Incubation for a further $24 \mathrm{~h}$ resulted in little change for the pig feed and wheat bran, but the DMD of the sugar-beet pulp doubled to 0.20 (SE 0.02). 


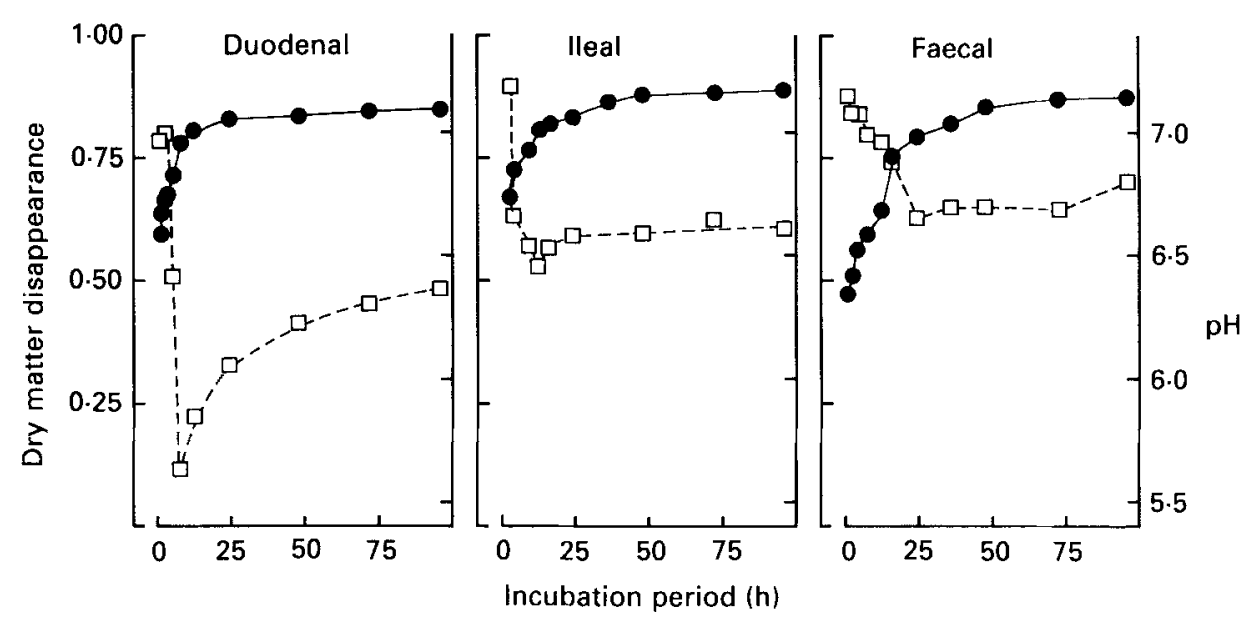

Fig. 2. Expt 2. In vitro dry matter disappearance (O) and $\mathrm{pH}(\square)$ of the media for pig feed incubated with duodenal, ileal and faecal inocula. For details of procedures, see p. 675.

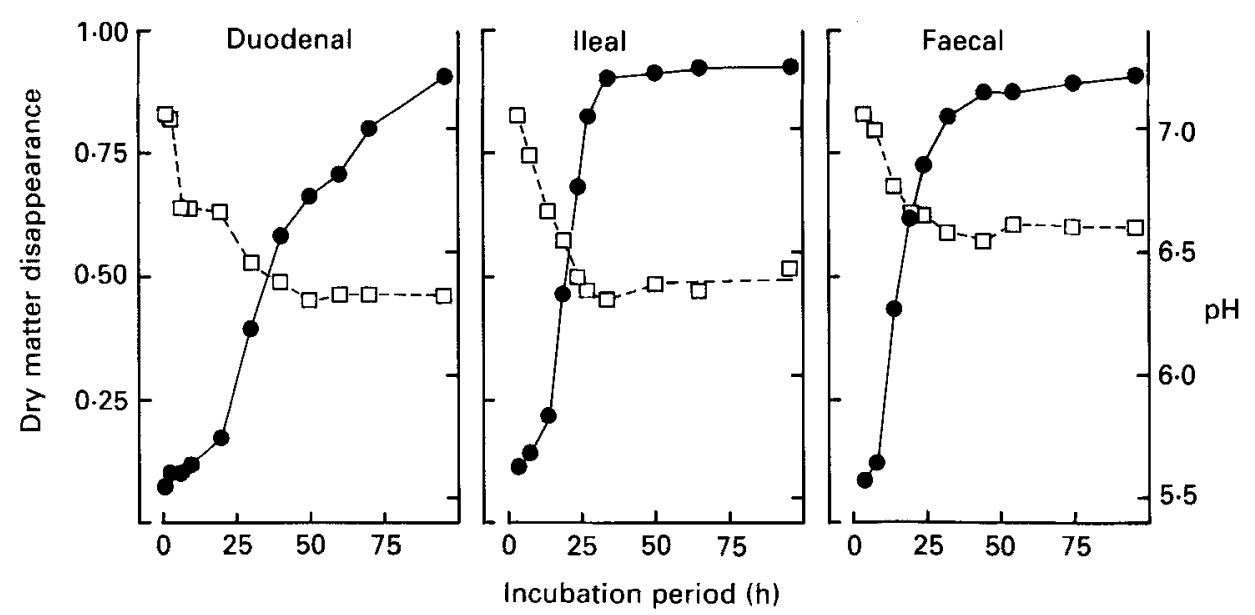

Fig. 3. Expt 2. In vitro dry matter disappearance $(\bullet)$ and $\mathrm{pH}(\square)$ of the media for sugar-beet pulp incubated with duodenal, ileal and faecal inocula. For details of procedures, see. p. 675.

\section{Expt 2}

Pig feed. The pig feed was rapidly solubilized by all three inocula, the rate and extent of DMD reflecting the high proportion of readily digestible nutrients present in the feed (Fig. 2). DMD with duodenal inoculum reached a plateau at about $0 \cdot 80$ after $12 \mathrm{~h}$ of incubation, while the $\mathrm{pH}$ dropped from $7 \cdot 1$ at $0.5 \mathrm{~h}$ to 5.6 after $8 \mathrm{~h}$, and increased again to about 6.3 after $26 \mathrm{~h}$. The solubilization by ileal inoculum reached a plateau after $24 \mathrm{~h}$, at about 0.88 , whereas the disappearance in the faecal inoculum continued up to $48 \mathrm{~h}$, but reached the same level. $\mathrm{pH}$ did not fall below 6.4 , and levelled out at about 6.6 after $24 \mathrm{~h}$ with both ileal and faecal inocula. The average standard errors for DMD were 0.004, 0.008 and 0.004 with duodenal, ileal and faecal inocula respectively. 


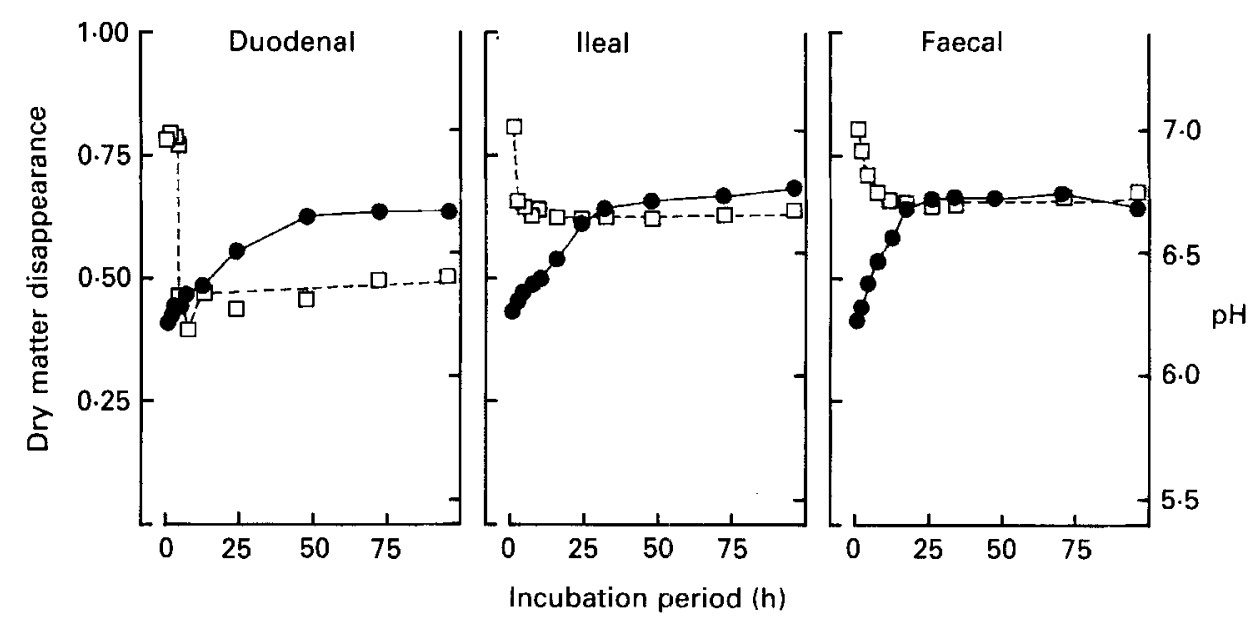

Fig. 4. Expt 2. In vitro dry matter disappearance (O) and $\mathrm{pH}(\square)$ of the media for wheat bran incubated with duodenal, ileal and faecal inocula. For details of procedures, see p. 675 .

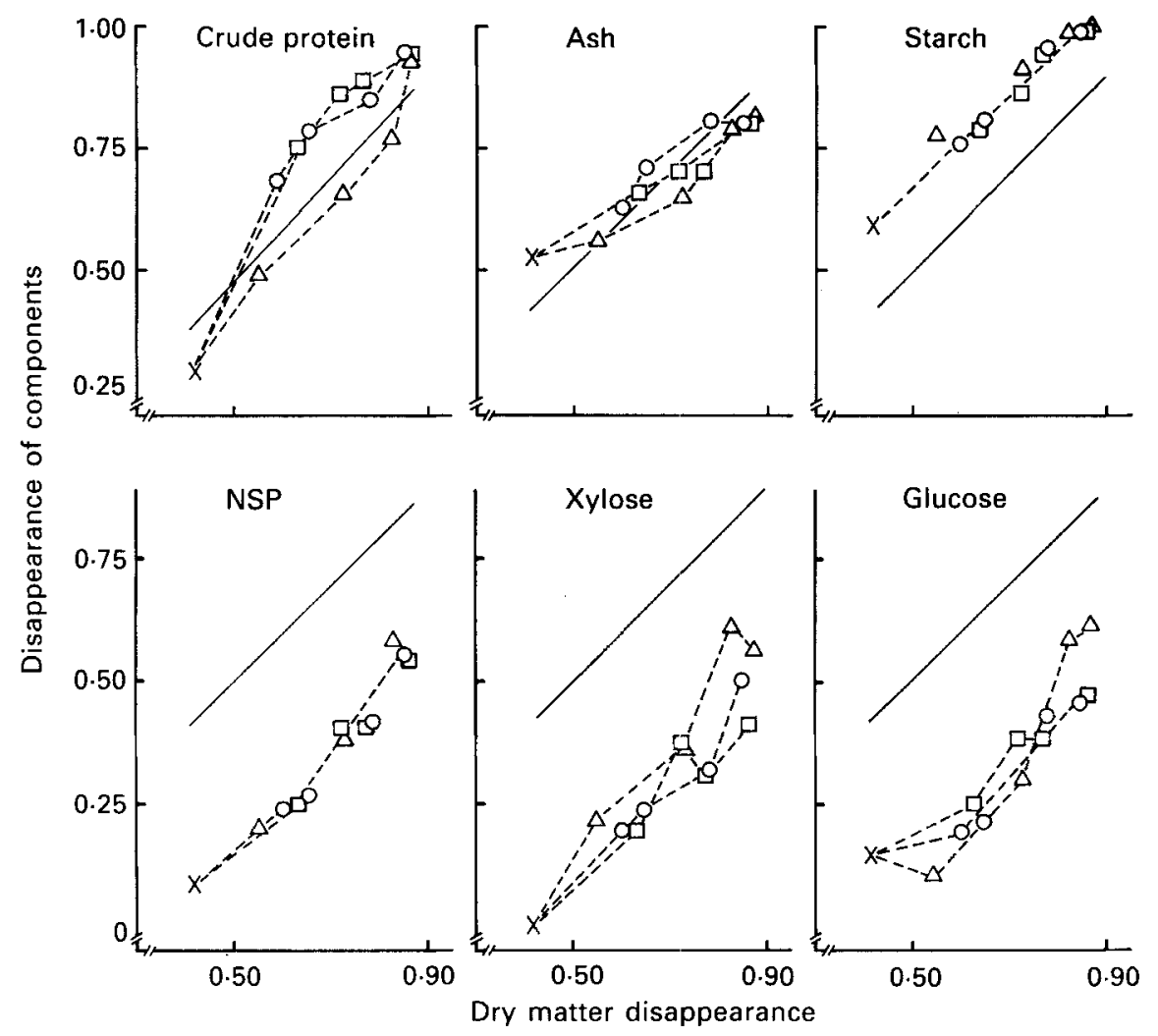

Fig. 5. Expt 3. In vitro disappearance of individual components of pig feed relative to dry matter disappearance when incubated with duodenal $(O)$, ileal $(\square)$ and faecal $(\Delta)$ inocula and washed with water $(x)$. ( - , Equivalence line. For details of procedures, see p. 675. NSP, non-starch polysaccharides. 
Table 3. Expt 3. Acetic, propionic, lactic and total organic acids produced $(\mathrm{g} / \mathrm{l})$ and dry matter disappearance $(D M D ; g / l)$ during in vitro incubation of the pig feed with duodenal, ileal and faecal inocula for different periods of time*

\begin{tabular}{|c|c|c|c|c|c|c|c|c|}
\hline \multirow[t]{2}{*}{ Inoculum } & \multirow{2}{*}{$\begin{array}{l}\text { Incubation } \\
\text { period (h) }\end{array}$} & \multicolumn{3}{|c|}{ DMD } & \multicolumn{3}{|c|}{ Organic acids } & \multirow[b]{2}{*}{ Total $\dagger$} \\
\hline & & Mean & $\mathrm{SE}$ & $n$ & Acetic & Propionic & Lactic & \\
\hline \multicolumn{9}{|l|}{ Duodenal } \\
\hline & 0.5 & $5 \cdot 51$ & 0.09 & 6 & nd & nd & 0.04 & 0.07 \\
\hline & 3 & 5.95 & 0.03 & 8 & 0.03 & nd & 0.62 & 0.72 \\
\hline & 10 & $7 \cdot 13$ & 0.02 & 12 & 0.77 & 0.74 & 4.59 & 6.58 \\
\hline & 96 & 7.74 & 0.06 & 13 & 1.79 & $2 \cdot 29$ & 0.39 & 5.69 \\
\hline \multicolumn{9}{|l|}{ Ileal } \\
\hline & 1 & 5.74 & 0.03 & 7 & 0.03 & nd & 0.03 & 0.06 \\
\hline & 4.5 & 6.55 & 0.05 & 9 & 0.41 & nd & 2.61 & 3.49 \\
\hline & 11 & 7.04 & 0.02 & 14 & $1 \cdot 14$ & 1.52 & 0.06 & $3 \cdot 19$ \\
\hline & 96 & 7.85 & 0.02 & 14 & 1.94 & $2 \cdot 16$ & nd & 4.66 \\
\hline \multicolumn{9}{|l|}{ Faecal } \\
\hline & $2 \cdot 5$ & 4.99 & 0.07 & 6 & 0.11 & 0.21 & 0.49 & 0.83 \\
\hline & $\begin{array}{l}12 \\
24\end{array}$ & $\begin{array}{l}6.60 \\
7.53\end{array}$ & 0.02 & 9 & 0.98 & $1 \cdot 16$ & nd & $2 \cdot 49$ \\
\hline & 24 & 7.53 & 0.02 & 14 & 1.29 & 1.41 & nd & $3 \cdot 23$ \\
\hline & 96 & 7.93 & 0.03 & 14 & 1.37 & 1.41 & nd & 3.52 \\
\hline
\end{tabular}

Sugar-beet pulp. The in vitro disappearance of sugar-beet pulp in all media was initially relatively low. On the other hand the DMD after $96 \mathrm{~h}$ of incubation exceeded 0.90 with all three inocula (Fig. 3). In vitro solubilization of sugar-beet pulp by duodenal inoculum had a pronounced lag phase up to $20 \mathrm{~h}$ of incubation. Following this, the solubilization proceeded gradually up to 0.91 after $96 \mathrm{~h}$, while the $\mathrm{pH}$ fell to about 6.3 . The ileal and faecal solubilization of sugar-beet pulp was more rapid than the duodenal, despite a lag phase of about $10 \mathrm{~h}$. Between 8 and $32 \mathrm{~h} 0 \cdot 70$ was solubilized, after which a plateau was reached at the same level as the final duodenal solubility $(0 \cdot 91) . \mathrm{pH}$ in ileal and faecal media was stable at about 6.4 and 6.6 respectively from $25 \mathrm{~h}$ and onwards. During the phase of more rapid solubilization the variability in DMD was greatest, but average SE of the means were $0.02,0.01$ and 0.005 for the duodenal, ileal and faecal inocula respectively.

Wheat bran. Bran was less susceptible to solubilization than the other two feeds; however, about 0.40 was solubilized within $1 \mathrm{~h}$ in all three media (Fig. 4). The solubilization of bran by duodenal inoculum progressed slowly, with an eventual disappearance of 0.64 after $96 \mathrm{~h}$. $\mathrm{pH}$ dropped during the first $5 \mathrm{~h}$ from the initial $7 \cdot 0$, and was stable at about $6 \cdot 3$ during the remainder of the incubation. The ileal and faecal in vitro incubations resulted in the disappearance of about 0.68 of the wheat bran, with most of this solubilization taking place within $30 \mathrm{~h}$ of incubation. $\mathrm{pH}$ never fell below 6.6 . The variability was small with average SE of the means of $0.005,0.006$ and 0.003 for the duodenal, ileal and faecal media respectively.

\section{Expt 3}

The losses of soluble and particulate matter for the digestion tubes when washed with water, shown as the $0 \mathrm{~h}$ DMD in Figs. $5-7$, varied considerably between feeds; 0.42 (pig feed), 0.08 (sugar-beet pulp), and 0.26 (wheat bran) with corresponding SE of means of $0.004,0.002$ and 0.007 . 


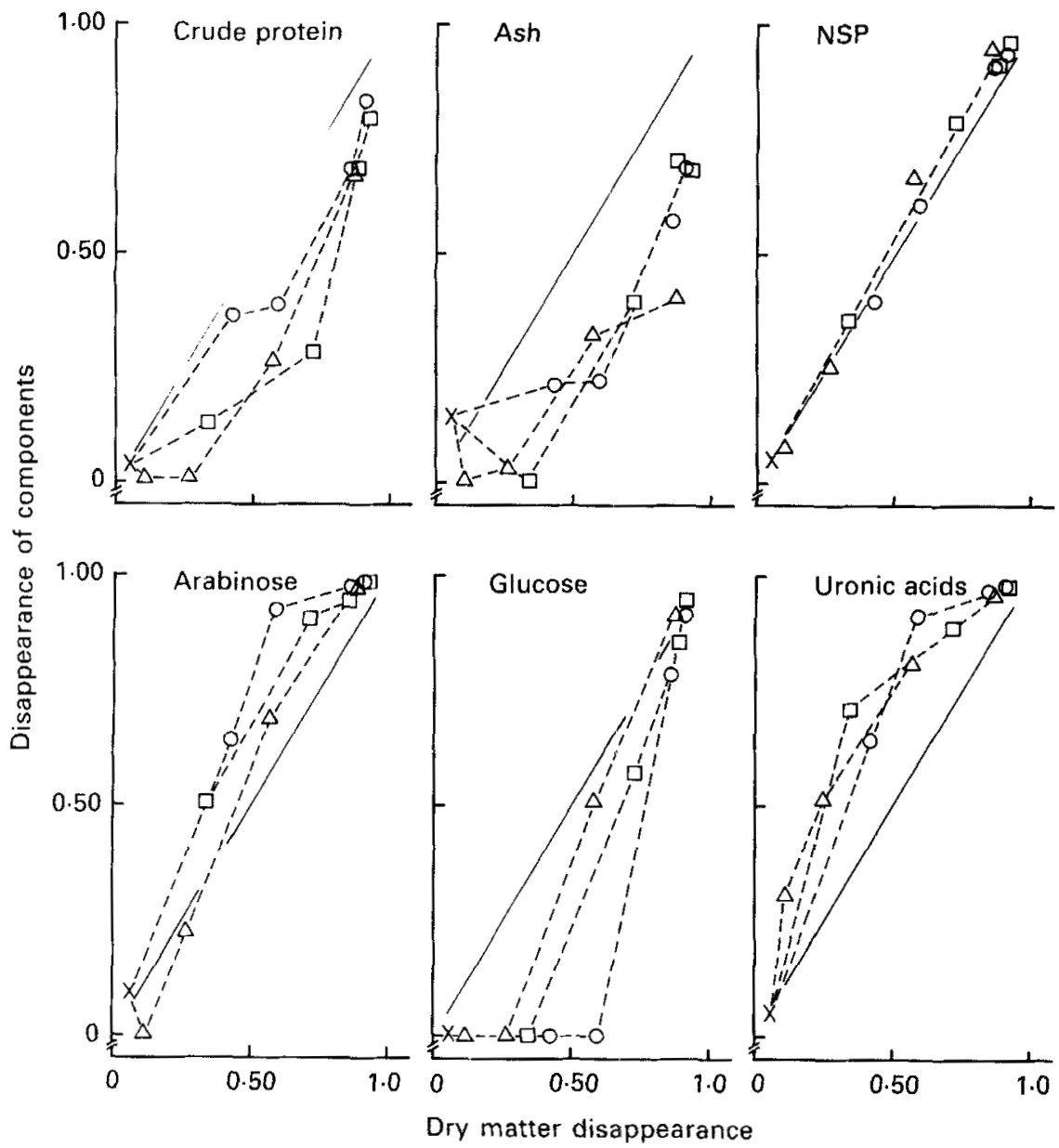

Fig. 6. Expt 3. In vitro disappearance of individual components of sugar-beet pulp relative to dry matter disappearance when incubated with duodenal $(O)$, ileal $(\square)$ and faecal $(\Delta)$ inocula and washed with water $(x)$. (-), Equivalence line. For details of procedures, see p. 675. NSP, non-starch polysaccharides.

Pig feed. For all inocula the in vitro DMD values after $96 \mathrm{~h}$ were in agreement with those observed in the previous experiment. Crude protein and starch generally disappeared at a greater rate than total dry matter, and were almost completely solubilized by $96 \mathrm{~h}$ in all three media. Indeed starch was essentially solubilized after $24 \mathrm{~h}$ in all inocula. Ash was solubilized at a somewhat slower rate than dry matter. The NSP fraction of the pig feed and its constituent residues disappeared at considerably slower rates and extents than dry matter, and this was especially pronounced for the glucose residues. The patterns of disappearance were similar in the three media, although the faecal inoculum seemed to be more potent against the xylose and glucose residues (Fig. 5). The production of organic acids was low during the first $3 \mathrm{~h}$ of duodenal $(0.72 \mathrm{~g} / \mathrm{l})$ and faecal $(0.83 \mathrm{~g} / \mathrm{l})$ incubation and for the first hour of ileal incubation (Table 3). The predominant product in duodenal medium during the first $10 \mathrm{~h}$ was lactic acid, but thereafter a shift to acetic and propionic acids was apparent $(96 \mathrm{~h})$. At $10 \mathrm{~h}$ similar amounts of organic acids were present in the duodenal medium to the dry matter lost $(6.58 v .7 \cdot 13 \mathrm{~g} / 1)$. As with the duodenal incubation, 
Table 4. Expt 3. Acetic, propionic, butyric and total organic acids produced $(\mathrm{g} / \mathrm{l})$ and dry matter disappearance (DMD; $g / l)$ during in vitro incubation of sugar-beet pulp with duodenal, ileal and faecal inocula for different periods of time*

\begin{tabular}{|c|c|c|c|c|c|c|c|c|}
\hline \multirow[t]{2}{*}{ Inoculum } & \multirow{2}{*}{$\begin{array}{l}\text { Incubation } \\
\text { period (h) }\end{array}$} & \multicolumn{3}{|c|}{ DMD } & \multicolumn{4}{|c|}{ Organic acids } \\
\hline & & Mean & SE & $n$ & Acetic & Propionic & Butyric & Total $\uparrow$ \\
\hline \multicolumn{9}{|l|}{ Duodenal } \\
\hline & 24 & 3.98 & 0.04 & 5 & $1 \cdot 70$ & 1.75 & 0.48 & $4 \cdot 29$ \\
\hline & 34 & $5 \cdot 45$ & 0.06 & 5 & $2 \cdot 16$ & 1.98 & $0.55^{\circ}$ & $4 \cdot 93$ \\
\hline & 60 & 7.90 & 0.06 & 8 & $2 \cdot 25$ & 1.90 & 0.82 & $5 \cdot 11$ \\
\hline & 96 & $8 \cdot 24$ & 0.03 & 14 & $2 \cdot 44$ & $2 \cdot 07$ & 1.00 & 5.69 \\
\hline \multicolumn{9}{|l|}{ Ileal } \\
\hline & 12 & $3 \cdot 13$ & 0.05 & 5 & $1 \cdot 22$ & 0.71 & 0.23 & $2 \cdot 21$ \\
\hline & 19 & 6.64 & 0.07 & 6 & $2 \cdot 97$ & $1 \cdot 32$ & 0.58 & $5 \cdot 04$ \\
\hline & 26 & $8 \cdot 05$ & 0.03 & 10 & 3.09 & $1 \cdot 35$ & 0.69 & $5 \cdot 21$ \\
\hline & 96 & $8 \cdot 39$ & 0.04 & 14 & $3 \cdot 34$ & 1.69 & 0.82 & 5.99 \\
\hline \multicolumn{9}{|l|}{ Faecal } \\
\hline & 10 & 1.02 & 0.02 & 5 & $0 \cdot 26$ & $0 \cdot 10$ & 0.03 & 0.39 \\
\hline & 15 & $2 \cdot 45$ & 0.08 & 5 & 0.92 & $0 \cdot 30$ & 0.14 & $1 \cdot 38$ \\
\hline & 24 & $5 \cdot 25$ & 0.04 & 10 & $1 \cdot 58$ & 0.55 & $0-45$ & $2 \cdot 63$ \\
\hline & 96 & 7.95 & 0.02 & 14 & $2 \cdot 30$ & 0.87 & 1.00 & $4 \cdot 39$ \\
\hline
\end{tabular}

* For details of procedures, see p. 675 .

$\dagger$ Total also includes: formic, isovaleric and lactic acids and ethanol.

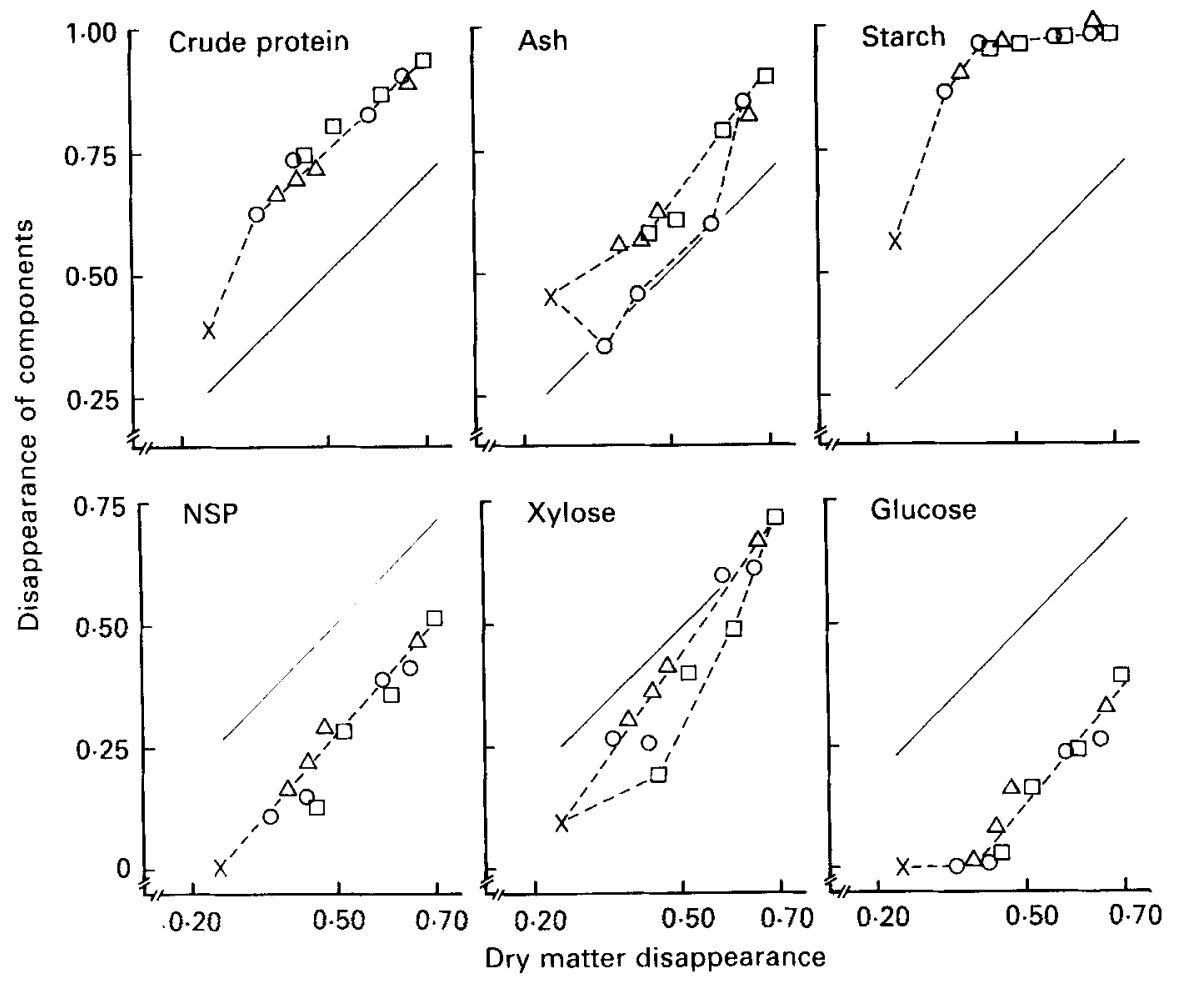

Fig. 7. Expt 3. In vitro disappearance of individual components of wheat bran relative to dry matter disappearance when incubated with duodenal $(O)$, ileal $(\square)$ and faecal $(\triangle)$ inocula and washed with water $(x)$. (-), Equivalence line. For details of procedures, see p. 675. NSP, non-starch polysaccharides. 
Table 5. Expt 3. Acetic, propionic, lactic and total organic acids produced $(\mathrm{g} / \mathrm{l})$ and $d r y$ matter disappearance $(D M D ; g / l)$ during in vitro incubation of wheat bran with duodenal, ileal and faecal inocula for different periods of time*

\begin{tabular}{|c|c|c|c|c|c|c|c|c|}
\hline \multirow[t]{2}{*}{ Inoculum } & \multirow{2}{*}{$\begin{array}{l}\text { Incubation } \\
\text { period }(\mathrm{h})\end{array}$} & \multicolumn{3}{|c|}{ DMD } & \multicolumn{4}{|c|}{ Organic acids } \\
\hline & & Mean & $\mathrm{SE}$ & $n$ & Acetic & Propionic & Lactic & Total \\
\hline \multicolumn{9}{|l|}{ Duodenal } \\
\hline & 0.5 & $3 \cdot 28$ & $0 \cdot 10$ & 5 & 0.01 & nd & 0.04 & $0 \cdot 10$ \\
\hline & 8 & 3.90 & 0.05 & 6 & 0.43 & 0.32 & $2 \cdot 18$ & $3 \cdot 14$ \\
\hline & 24 & $5 \cdot 31$ & 0.02 & 7 & 1.24 & $1 \cdot 84$ & 0.20 & 3.93 \\
\hline & 96 & 5.89 & 0.01 & 8 & 1.73 & $2 \cdot 14$ & nd & $4 \cdot 56$ \\
\hline \multicolumn{9}{|l|}{ Ileal } \\
\hline & 1 & $4 \cdot 11$ & 0.02 & 5 & 0.01 & 0.04 & 0.06 & $0 \cdot 13$ \\
\hline & 9 & $4 \cdot 63$ & 0.02 & 6 & 0.91 & $1 \cdot 29$ & nd & $2 \cdot 59$ \\
\hline & 22 & $5 \cdot 51$ & 0.06 & 7 & 1.51 & 1.63 & nd & $3 \cdot 46$ \\
\hline & 96 & $6 \cdot 33$ & 0.02 & 8 & 1.86 & 1.87 & nd & $4 \cdot 20$ \\
\hline \multicolumn{9}{|l|}{ Faecal } \\
\hline & 1 & 3.58 & 0.01 & 5 & 0.01 & nd & 0.01 & $0 \cdot 03$ \\
\hline & 6 & 3.99 & 0.02 & 5 & 0.32 & 0.18 & 0.17 & 0.89 \\
\hline & 12 & $4 \cdot 29$ & 0.04 & 7 & $0 \cdot 91$ & 0.55 & nd & 1.61 \\
\hline & 96 & 6.00 & 0.02 & 8 & 1.57 & 1.03 & nd & 3.06 \\
\hline
\end{tabular}

nd, not detected.

* For details, see p. 675.

$\uparrow$ Total also includes: formic, butyric and isovaleric acids and ethanol.

lactic acid was the major product in the early stages of ileal and faecal incubations $(4.5 \mathrm{~h}$ and $2.5 \mathrm{~h}$ respectively), later shifting to acetic and propionic acids. However, this shift occurred earlier in these incubations than in the duodenal ones.

Sugar-beet pulp. The rate and extent of crude protein disappearance from the sugar-beet pulp was considerably greater in the duodenal incubations than with ileal and, especially, faecal inocula (Fig. 6). A relative retention of ash at the early stages of the ileal and faecal incubations was observed, and this persisted after $96 \mathrm{~h}$ with the faecal medium. The degradation of NSP closely followed that of the dry matter, not surprisingly as it is the major component. The rates of disappearance were high for arabinose and uronic acid residues, while glucose residues were solubilized at a slower rate than dry matter and NSP, especially with the duodenal medium (Fig. 6). The predominant organic acids produced in the three media were acetic and propionic, with slightly more of the former (Table 4). The high production of organic acids in the duodenal medium was striking, exceeding the DMD $(4.29$ v. $3.98 \mathrm{~g} / \mathrm{l})$ when incubated for $24 \mathrm{~h}$.

Wheat bran. Crude protein and starch disappeared considerably faster and to a greater extent than dry matter (Fig. 7). The patterns of disappearance were similar for these two components in all media, while the disappearance of ash was more variable, with the duodenal medium the least potent. Xylose residues were more susceptible to solubilization than the sum of NSP residues, whereas the opposite was found for glucose residues. Notable was the agreement between the three media. As for pig feed, a considerable proportion of dry matter was lost in all three media before any significant production of organic acids was apparent (Table 5). The production of organic acids was higher with the duodenal incubation than with the ileal, which again exceeded that of the faecal incubation. Lactic acid was quantitatively the major product in the duodenal medium when bran was incubated for $8 \mathrm{~h}$, but with longer incubations acetic and propionic acids were the predominant products with all inocula. 


\section{DISCUSSION}

The animals were mature at the onset of the experiment, with a live weight of about $170 \mathrm{~kg}$, and their digestive capacities were presumably greater than those of smaller pigs. The effect of this on the activity of in vitro inocula is unknown, but it could be expected that the same degradation end-point would be reached, even should the disappearance rate differ. All in vitro procedures suffer from certain inadequacies, including the loss of soluble and particulate matter and the accumulation of digestion end-products. Such deficiencies may be at least partly overcome by altering the experimental procedure, but often this involves an increase in complexity with a resultant reduction in sample throughput. The present method was designed to use common laboratory equipment and to allow a large number of samples to be studied simultaneously, and in our laboratory up to 250 incubations are run concurrently.

\section{Expt 1}

Initially in vitro incubations, particularly for shorter periods of time with ileal and faecal inocula, were very difficult to filter, and thus the effects of pre-centrifugation of the inocula were tested. Centrifugation of the ileal inocula resulted in increased DMD and lower variabilities, probably an effect of the removal of small particles and mucus that would not only contribute by weight, but also hinder filtration and washing of the residues. However, centrifugation at higher speeds should be avoided as this can remove certain fractions of the bacterial population, especially those bound to particles.

Decreasing the sample particle size led, as expected, to an increase in buffer solubility, including particle loss. However, no difference between samples from the different screens was apparent after $45 \mathrm{~h}$ incubation with all inocula, suggesting that the components lost, including particles, from the finely ground sample were potentially degradable. A screen size of $1 \mathrm{~mm}$ was chosen, as previously proposed by Furuya et al. (1979), as this would ensure a standardized particle size even in highly processed feeds, and should decrease variability by allowing a more representative sample to be taken.

Braude et al. (1976) and Graham \& Åman (1986) measured pH at different sites in the small intestine of the pig and found values of about 4-6 and 7 in duodenal and ileal digesta respectively. Holzgraefe et al. (1985) proposed that a $\mathrm{pH}$ of 5.8 was optimal for in vitro incubations using pig caecal inoculum. However, results in the present study show that a $\mathrm{pH}$ closer to 7.0 was more suitable under the conditions employed here. The initial $\mathrm{pH}$ of the media will also depend on the buffering capacity of the inocula, and on the size and type of feed sample.

The study undertaken into the effects of the buffer on the solubilization of the feeds established that DMD up to $48 \mathrm{~h}$ was comparable with that achieved by washing with water, and it was concluded that no further investigation on solubility in the buffer was necessary in this context.

\section{Expts 2 and 3}

Although different in rate, the general patterns of DMD in all three media were similar for each feed. This similarity was further illustrated when the disappearance of feed components was related to DMD (Figs. 5-7), when the influence of rate is removed. The in vitro incubations were characterized by the rapid solubilization of, in particular, starch and protein, followed by the slower solubilization of the NSP. It is likely that in the duodenal media this initial rapid solubilization was primarily the result of the activity of pancreatic enzymes, whereas in the other two media this would be due to microbial activity. That the 
bacteria in the duodenal inoculum were not as active as those in the other two media was shown by the slow rate of disappearance of sugar-beet pulp in the former. The presence of readily digestible components in the pig feed and the wheat bran probably stimulated bacterial proliferation, and thus little or no lag phase was apparent, particularly in the duodenal medium.

The variation within the in vitro method was rather small, with standard errors of the mean generally not exceeding 0.01 , but was, predictably, larger during periods of rapid solubilization. Although not fully investigated here, it would thus appear that, as for human faecal inocula (McBurney \& Thompson, 1987), the activities of the three inocula did not differ greatly between collections.

As could be expected, the type and quantity of organic acids produced and the $\mathrm{pH}$ attained in the ileal medium were intermediate between those in the duodenal and faecal media. As is the situation in vivo (Alexander \& Davies, 1963; Argenzio \& Southworth, 1974), lactic acid was produced in greater amounts when starchy feeds were digested, and was the primary metabolite during the initial stages of incubation, particularly in the duodenal medium. This lactate was later metabolized to acetate and propionate, with relatively more propionate in the duodenal and ileal media than in the faecal medium. No lactate was detected in any of the media following incubation of sugar-beet pulp. The greater production of total organic acids in the duodenal incubations was probably due to the presence of nutrients, including partially degraded starch, in the inoculum (Graham $e t$ $a l .1986 b$ ). The presence of greater amounts of lactic acid in the media led to a depression in $\mathrm{pH}$, as seen in the initial stages of the duodenal incubation with the pig feed. Further metabolism of the lactate led to an increase in $\mathrm{pH}$. Experience with ruminant bacteria would suggest that $\mathrm{pH}$ values below 6 can result in reduced fibre degradation (Van Soest, 1982), and thus more than $0.5 \mathrm{~g}$ starchy feeds should not be investigated in this type of system.

Although the patterns of disappearance of components relative to DMD were very similar between inocula, there was an indication that protein disappearance in the faecal medium was relatively slower. This could be due to a reduced protein solubilization per se, but is more likely the result of bacterial attachment to the undigested residues. As also shown in vivo (Graham et al. 1986a), undegraded sugar-beet pulp could bind and retain minerals. The potential degradability of the NSP in the feeds varied from about 0.5 in the wheat bran to 0.95 in the sugar-beet pulp. Whereas glucose residues in the wheat bran and the sugar-beet pulp (predominantly from cellulose) were initially resistant to solubilization, those in the pig feed, where more than one-third of the glucose residues come from mixedlinked $\beta$-glucans (Graham et al. 1986a), disappeared relatively more quickly.

The similarities in degradation patterns of individual components between the three inocula indicate that any one could be used to illustrate the digestion in the different compartments of the pig intestine. That the extent and pattern of solubilization, even for fibre components, was similar between duodenal, ileal and faecal inocula is rather surprising. This shows that the bacteria in the duodenal digesta have, or can develop, the ability to degrade dietary fibre, although the importance of such degradation in vivo is unknown. The fibre-degrading abilities of bacteria in duodenal and ileal digesta have been demonstrated previously (Graham et al. 1986 b). The similarity in the pattern of degradation relative to DMD would suggest that the bacterial populations, irrespective of type, degraded the feed components in an order primarily determined by their availability in the feeds.

In conclusion, the in vitro incubations were shown to have a low variability, and to degrade both readily available and less susceptible feed components. The patterns of dry matter and individual component disappearances were quite similar in the three inocula, 
with the exception of crude protein, where the build-up of microbial mass was probably responsible for the reduction in degradation observed with ileal and faecal media.

Before an in vitro method for studying digestion in simple-stomached animals can be widely used, further studies are required into, for example, the within- and between-pig variation, and the effect of donor-pig diet and age on inocula activity. Inclusion of standard samples could be used to allow the comparison of in vitro digestibilities between runs.

It is proposed that a combination of a short $(6-12 \mathrm{~h})$ and a long $(48-72 \mathrm{~h})$ in vitro incubation could be employed to simulate in vivo digestion in the pig. The short incubation period would represent the readily digested nutrients and the difference between the long and the short incubations would estimate the fermented components. As the nutritive value of a feed is dependent on the site of absorption, the incubation times in the different media, as well as the combination of media, require further study.

The authors gratefully acknowledge the help of Drs G. Björnhag and E. Jonsson in pig cannulation, of Dr K. Larsson and B. Andersson at the National Swedish Laboratory for Agricultural Chemistry for assistance with the analysis of the organic acids, and of the technical staff of the Division of Feed Chemistry. This work was financially supported by The Swedish Council for Forestry and Agricultural Research.

\section{REFEREN CES}

Alexander, F. \& Davies, M. E. (1963). Production and fermentation of lactate by bacteria in the alimentary canal of the horse and pig. Journal of Comparative Pathology and Therapeutics 73, 1-8.

Åman, P. \& Hesselman, K. (1984). Analysis of starch and other main constituents of cereal grains. Swedish Journal of Agricultural Research 14, 135-139.

Anon. (1971). Determination of crude oils and fats. Official Journal of the European Community 1297, 995-997.

Argenzio, R. A. \& Southworth, M. (1974). Sites of organic acid production and absorption in gastrointestinal tract of the pig. American Journal of Physiology 228, 454-460.

Association of Official Analytical Chemists. (1975). Official Methods of Analysis, 12th ed. Washington, DC: AOAC.

Braude, R., Fulford, R. J. \& Low, A. G. (1976). Studies on digestion and absorption in the intestines of growing pigs. Measurements of the flow of digesta and pH. British Journal of Nutrition 36, 497-510.

Clunies, M. \& Leeson, S. (1984). In vitro estimation of dry matter and crude protein digestibility. Poultry Science 63, 89-96.

Dunn, O. J. \& Clark, V. A. (1974). Applied Statistics: Analysis of Variance and Regression. New York: John Wiley.

Furuya, S., Sakamoto, K. \& Takahashi, S. (1979). A new in vitro method for the estimation of digestibility using the intestinal fluid of the pig. British Journal of Nutrition 41, 511-520.

Graham, H. \& Åman, P. (1986). Circadian variation in the composition of duodenal and ileal digesta from pigs fitted with T-cannulas. Animal Production 43, 133-140.

Graham, H., Hesselman, K. \& Aman, P. (1986a). The influence of wheat bran and sugar-beet pulp on the digestibility of dietary components in a cereal-based pig diet. Journal of Nutrition 116, 242-251.

Graham, H., Hesselman, K., Jonsson, E. \& Åman, P. (1986b). Influence of $\beta$-glucanase supplementation on digestion of a barley-based diet in the pig gastrointestinal tract. Nutrition Reports International 34, $1089-1096$.

Holzgraefe, D. P., Fahey, G. C. Jr \& Jensen, A. H. (1985). Influence of dietary alfalfa : orchardgrass hay and lasalocid on in vitro estimates of dry matter digestibility and volatile fatty acid concentrations of cecal contents and rate of digesta passage in sows. Journal of Animal Science 60, 1235-1246.

Just, A., Fernández, J. A. \& Jørgensen, H. (1983). The net energy value of diets for growth in pigs in relation to the fermentative processes in the digestive tract and the site of absorption of the nutrients. Livestock Production Science 10, 171-186.

Larsson, K. \& Bengtsson, S. (1983). Bestämning av lätt tillgängliga kolhydrater i växtmaterial (Determination of readily available carbohydrates in plant material). Method no. 22. Uppsala: National Swedish Laboratory for Agricultural Chemistry.

Lindgren, E. (1979). Vallfodrets näringsvärde bestämt in vivo och med olika laboratoriemetoder (The nutritional value of roughages determined in vivo and by laboratory methods). Report no. 45. Uppsala: Swedish University of Agricultural Science, Department of Animal Nutrition.

McBurney, M. I. \& Thompson, L. U. (1987). Effect of human faecal inoculum on in vitro fermentation variables. British Joumal of Nutrition 58, 233-243. 
Mason, V. C. (1983). Microbial digestion in the hind-gut of the pig. International Journal for Vitamin and Nutrition Research 25, 27-38.

SAS Institute Inc. (1982). SAS User's Guide: Statistics. Cary, NC: SAS Institute Inc.

Theander, O.\& Åman, P. (1979). Studies on dietary fibres. 1. Analysis and chemical characterization of watersoluble and water-insoluble dietary fibres. Swedish Journal of Agricultural Research 9, 97-106.

Theander, O. \& Westerlund, E. (1986). Studies on dietary fiber. 3. Improved procedures for analysis of dietary fiber. Journal of Agricultural and Food Chemistry 34, 330-336.

Van Soest, P. J. (1982). Nutritional Ecology of the Ruminant. Corvallis, Oregon: O \& B Books, Inc.

Vervaeke, I. J., Decuypere, J. A., Dierick, N. A. \& Henderickx, H. K. (1979). Quantitative in vitro evaluation of the energy metabolism influenced by virginiamycin and spiramycin used as growth promotors in pig nutrition. Journal of Animal Science 49, 846-856. 